\title{
Prevention of Malaria Infection in Travelers: A Review
}

\section{Sajida Sbouil ${ }^{1}$ and Ahmed Tabbabi2*}

1Faculty of Medicine of Monastir, Monastir University, Monastir, Tunisia

${ }^{2}$ Department of Hygiene and Environmental Protection, Ministry of Public Health, Tunis, Tunisia

\section{Mini Review \\ Volume 2 Issue 1}

Received Date: February 15, 2018

Published Date: March 02, 2018

*Corresponding author: Ahmed Tabbabi, Department of Hygiene and Environmental Protection, Ministry of Public Health University, Tunisia, Email: tabbabiahmed@gmail.com

\section{Abstract}

Malaria is dangerous if it is not treated as soon as the first peaks of fever appear and deaths are always linked to a delay in the administration of anti malarial drugs. During the transmission season in countries and territories where there is a risk of malaria, all non-immune travelers exposed to mosquito bites, especially between bedtime and sunrise, are at risk of malaria. Although well-managed anti malarial chemoprophylaxis provides about $90-95 \%$ protection, personal protective measures remain one of the essential pillars of malaria prevention. Many regions are therefore newly considered as low or moderate risk areas for malaria. The International Congress of Tropical Medicine 2015 in Quebec City has helped revive the debate and oppose three political currents. Preservatives (represented by the Centers for Disease Control in the United States) advocate the need for chemoprophylaxis prevention due to its efficiency. The Liberals (represented by Holland) offer protection against mosquito bites only to avoid the risk of non-severe side effects of chemoprophylaxis. The Swiss offer a reserve treatment to take in case of feverish condition waiting for a medical consultation because chemoprophylaxis in these areas puts the traveler at greater risk of suffering from the side effects of prophylaxis than of malaria itself.

Keywords: Malaria; Travelers; Chemoprophylaxis; Personal protective measures; Prevention

\section{Malaria in the World}

Malaria is caused by a protozoan parasite of the genus Plasmodium. Human malaria is caused by four different Plasmodium species: P. falciparum, P. malariae, $P$. ovale and $P$. vivax. Human is occasionally infected with Plasmodium species that normally parasitize animals, eg $P$. knowlesi. No case of human-mosquito-human transmission of these "zoonotic" forms of malaria has yet been reported.

Malaria is a major public health challenge. In 2015, there were 214 million cases and 438,000 deaths [1], the largest burden in the poorest countries, mainly in subSaharan Africa ( $88 \%$ of cases). These cases are mainly due to $P$. falciparum, the most prevalent species and associated with the highest mortality rate, and P. vivax, the most geographically extensive species. Since the year 2000 , a lot of effort has been made to reduce the overall incidence $(-37 \%)$ and mortality $(-60 \%)$ of malaria in fifteen years [1]. However, these figures come mainly from the decrease in $P$. falciparum, mobilizing the majority of efforts and funding [2]. Indeed, P. vivax does not show the same evolution. Eradication is more difficult because of greater biological complexity $[3,4]$. The proportion of $P$. vivax cases increases in parallel with the 
decrease of those due to P. falciparum, and re-emergence is even probably in some areas, such as Ethiopia and Eritrea [1]. Imported P. vivax malaria cases are on the rise in some developed countries mainly because of migrants from the Horn of Africa [5].

\section{Diagnosis and Treatment}

Malaria is dangerous if it is not treated as soon as the first peaks of fever appear and deaths are always linked to a delay in the administration of anti malarial drugs. The rapid diagnostic test allows a diagnosis in fifteen minutes. A recent study, conducted in Lausanne, aimed at evaluating a strategy based on rapid diagnostic test coupled with microscopy during working hours, showed that such an attitude allowed a reduction of two hours on average until the result of the first malaria test [6]. An anti malarial treatment, intravenously in the presence of clinical signs of danger or orally, can thus be initiated immediately, guarantee of good evolution. WHO recommends a combination therapy with artemisinin [7].

\section{Risk for Travelers}

During the transmission season in countries and territories where there is a risk of malaria, all nonimmune travelers exposed to mosquito bites, especially between bedtime and sunrise, are at risk of malaria. Previously semi-immune travelers, who have lost some or all of their immunity because they have been in safe countries or zones for at least 6 months, are also vulnerable. Children of people who have migrated to safe countries or areas are at particular risk when returning to malarious areas to visit friends or relatives.

Most cases of $P$. falciparum malaria in travelers occur because they do not follow the prophylactic regimen or take appropriate medications or precautions against mosquito bites. Studies of traveler behavior have shown that adherence to chemoprophylaxis can be improved if travelers are informed of the risk of infection and convinced of the benefits of prevention. P. vivax or P. ovale malaria may occur late despite effective prophylaxis because these parasites cause relapses that cannot be prevented by the currently recommended prophylaxis.

The risk of malaria is unevenly distributed in places where the disease is widespread. Travelers to countries or areas where malaria transmission varies by region should be aware of the risk of infection in the areas they are visiting. If they cannot obtain accurate information before leaving, it is recommended that they take the highest risk precautions listed in the country or territory.
These precautions can be adapted if the traveler gets more information on arrival. This is especially true for people who travel backpacking in remote locations and traveling to areas where health facilities are difficult to access. Travelers who spend the night in rural areas are perhaps the most exposed.

\section{Prevention of Malaria Infection in Travelers}

Although well-managed anti malarial chemoprophylaxis provides about $90-95 \%$ protection, personal protective measures remain one of the essential pillars of malaria prevention. In a double-blind study, $85 \%$ of travelers reported mild side effects independent of the prescribed antimalarial drug (mefloquine, atovaquone / proguanil, doxycycline and chloroquine / proguanil) [8]. Anopheles, mosquitoes responsible for the transmission of malaria, has a nocturnal activity: from dusk until sunrise. For better protection, it is essential to combine several measures of personal protection. The use of impregnated mosquito nets has been largely effective [9]. In order to protect oneself indoors, it is also important to apply mosquito nets to windows and doors. WHO also recommends several insecticides that can be used for residual indoor residual spraying [10]. On the outside, it is proposed to wear loose, long and light clothing, to which it is possible to apply a pyrethroid insecticide to increase its effectiveness. The application of repellents on the skin is also indicated.

Malaria in pregnant women is more often severe and carries a higher risk of death and increased maternal-fetal complications [11]. When it is not possible to shift the stay in endemic areas, it is essential to advise the pregnant woman to protect herself optimally against mosquito bites. Pregnant women would be twice as likely to attract anopheles and leave their bed twice as often during the night as non-pregnant women [12]. The use of impregnated mosquito nets and pyrehtroids is safe during pregnancy $[13,14]$. At present, mefloquine is the only antimalarial drug that can be prescribed for chemoprophylaxis during pregnancy and lactation $[15,16]$. During breastfeeding, this treatment is recommended as soon as the child has reached a weight of $5 \mathrm{~kg}$ [17]. No termination of pregnancy is indicated during the accidental taking of an antimalarial during pregnancy.

Adherence to chemoprophylaxis and personal protection measures during long stays is poor $[18,19]$. Teaching about preventing malaria improves adherence [20]. The different possible strategies, their advantages and disadvantages must be discussed with the traveler 
[19-22]. Personal protective measures are effective with minimal toxicity. Knowing that they are not well followed, the focus should be on using mosquito nets impregnated on the bed and on windows and doors. While the risk of malaria increases linearly over time, the risk of new side effects increases at the beginning of anti malarial use, then remains constant or even decreases thereafter [23]. Long-term chemoprophylaxis is strongly recommended for high malaria risk, as well as for pregnant women, infants and travelers with much comorbidity.

In particular, the traveler must be informed of the symptoms of malaria and be given early diagnosis and treatment in all febrile conditions up to one year after returning from travel. Rapid tests have largely been shown to be effective in the diagnosis of malaria [24,25]. On the other hand, their use by travelers independently cannot be recommended because they do not use them adequately [26-28].

The risk of malaria is proportional to the length of stay. Long-stay travelers in endemic areas need to be aware of the risk they are exposed to as well as effective preventive measures: vector protection and chemoprophylaxis. Special emphasis should be placed on the use of nighttreated mosquito nets and doors and windows. When chemoprophylaxis is indicated, it should be prescribed during the first three to six months of stay. Thereafter, advice on chemoprophylaxis can be individualized, while informing the traveler of the advantages and disadvantages of the various possible strategies: continuous chemoprophylaxis, seasonal, emergency treatment.

\section{Challenges of Malaria Prevention in Low Risk Areas}

The number of international travelers surpassed one billion in 2012, and could double by 2030 [29]. At the same time, the global incidence of malaria has decreased by $37 \%$ between 2000 and 2015, and there is a decline of more than $75 \%$ in more than half of the countries with active transmission [30,31]. Many regions are therefore newly considered as low or moderate risk areas for malaria, mainly in Latin America and Southeast Asia. This decline is the result of a major effort through impregnated mosquito net distribution campaigns, the promotion of rapid diagnostic tests and more effective treatments based on artemisinin derivatives.

In terms of impact for the traveler, these figures call into question certain prevention strategies [32,33]. While anti malarial chemoprophylaxis, with mosquito-bite prevention measures in high-endemic areas, remains appropriate, there are various recommendations for areas of low or moderate risk of transmission [34-36].

The International Congress of Tropical Medicine 2015 in Quebec City has helped revive the debate and oppose three political currents. Preservatives (represented by the Centers for Disease Control in the United States) advocate the need for chemoprophylaxis prevention. Their arguments were that offer maximum protection for a lifethreatening disease and very effective prevention if taken properly [37]. The Liberals (represented by Holland) offer protection against mosquito bites only. Their arguments were the risk of non-severe side effects of chemoprophylaxis in $80 \%$ of cases, severe in $6-11 \%$ [38], and a rare use of reserve treatment in practice [39]. The Swiss offer a reserve treatment to take in case of feverish condition waiting for a medical consultation. Their arguments indicated that chemoprophylaxis in these areas puts the traveler at greater risk of suffering from the side effects of prophylaxis than of malaria itself $[40,41]$, adherence to chemoprophylaxis is in practice 30 $50 \%$ only $[42,43]$.

\section{References}

1. WHO (2015) World Malaria Report 2015, World health Organization.

2. Gething PW, Elyazar IRF, Moyes CL, David L Smith, Katherine E Battle, et al. (2012) A long neglected world malaria Map: Plasmodium vivax endemicity in 2010. PLoS Negl Trop Dis 6(9): e1814.

3. WHO (2015) Global Malaria Programme. Control and elimination of Plasmodium vivax malaria: A technical brief. World Health Organization.

4. Sattabongkot J, Tsuboi T, Zollner GE (2004) Plasmodium vivax transmission: Chances for control. Trends Parasitol 20: 192-198.

5. E peron G, Durieux S, Mauris A (2017) Malaria incidence in Switzerland from 2005 to 2015 and recent outbreak of imported Plasmodium vivax malaria. Swiss Med Wkly 24: 147.

6. Rossi IA, D Acremont V, Prod'Hom G, Genton B (2012) Safety of falciparum malaria diagnostic strategy based on rapid diagnostic tests in returning travellers and migrants: A retrospective study. Malar J 11: 377.

7. WHO (2013) Guidelines for the treatment of malaria, $2^{\text {nd }}(E d n$.$) .$ 
8. Schlagenhauf P, Tschopp A, Johnson R, (2003) Tolerability of malaria chemoprophylaxis in non immune travellers to Sub-Saharan Africa: Multicentre, randomised, double blind, four arm study. BMJ 327: 1078.

9. Lengeler C (2004) Insecticide-treated bed nets and curtains for preventing malaria. Cochrane Database Syst Rev 2: CD000363.

10. World health organization (2009) WHO recommended insecticides for indoor residual spraying against malaria vectors. Geneva: World health organization.

11. McGready R, Ashley EA, Nosten F, (2004) Malaria and the pregnant traveller. Travel Med Infect Dis 2(3-4): 127-142

12. Lindsay S, Ansell J, Selman C, Val Cox, Katie Hamilton, et al. (2000) Effect of pregnancy on exposure to malaria mosquitoes. Lancet 355: 1972.

13. McGready R, Hamilton KA, Simpson JA, Luxemburger C, Edwards R, et al. (2001) Safety of the insect repellent $\mathrm{N}, \mathrm{N}$-diethyl-M-toluamide (DEET) in pregnancy. Am J Trop Med Hyg 65: 285-289.

14. McGready R, Simpson JA, Htway M, White NJ, Nosten F, et al. (2001) A doubleblind randomized therapeutic trial of insect repellents for the prevention of malaria in pregnancy. Trans R Soc Trop Med Hyg 95: 137-138.

15. Phillips-Howard PA, Steffen R, Kerr L, Vanhauwere B, Schildknecht J, Fuchs E, et al. (1998) Safety of mefloquine and other antimalarial agents in the first trimester of pregnancy. J Travel Med 5: 121-126.

16. Schlagenhauf $P$ (1999) Mefloquine for malaria chemoprophylaxis 1992-1998: A review. J Travel Med 6: 122-133.

17. Schlagenhauf P, Petersen E (2008) Malaria chemoprophylaxis: Strategies for risk groups. Clin Microbiol Rev 21: 466-472.

18. Chen LH, Wilson ME, Schlagenhauf P (2006) Prevention of malaria in long-term travelers. JAMA 296: 2234-2244.

19. Toovey S, Moerman F, Van GA (2007) Special infectious disease risks of expatriates and long-term travelers in tropical countries. Part I: malaria. J Travel Med 14(1): 50-60.
20. Roukens AH, Berg J, Barbey A, Visser LG (2008) Performance of self-diagnosis and standby treatment of malaria in international oilfield service employees in the field. Malar J 7: 128.

21. Schlagenhauf P, Petersen E. (2008) Malaria chemoprophylaxis: Strategies for risk groups. Clin Microbiol Rev 21: 466-472.

22. Schlagenhauf P, Rietveld AEC (2008) Special Groups: Pregnant women, infants, and young children. In: editor. Travelers' Malaria. $2^{\text {nd }}$ (Edn.), Hamilton: BC Decker pp: 214-227.

23. Hughes C, Tucker R, Bannister B, Bradley DJ (2003) Malaria prophylaxis for long-term travellers. Commun Dis Public Health 6: 200-208.

24. Marx A, Pewsner D, Egger M, Nüesch R, Bucher HC, et al. (2005) Meta-analysis : Accuracy of rapid tests for malaria in travelers returning from endemic areas. Ann Intern Med 142: 836-846.

25. Ochola LB, Vounatsou P, Smith T, Mabaso ML, Newton CR (2006) The reliability of diagnostic techniques in the diagnosis and management of malaria in the absence of a gold standard. Lancet Infect Dis 6(9): 582-588.

26. Funk M, Schlagenhauf P, Tschopp A, Steffen R (1999) Mala Quick versus Para Sight F as a diagnostic aid in travellers' malaria. Trans R Soc Trop Med Hyg 93: 268-272.

27. Jelinek T, Amsler L, Grobusch MP, Nothdurft HD (1999) Self-use of rapid tests for malaria diagnosis by tourists. Lancet 354: 1609.

28. Trachsler M, Schlagenhauf P, Steffen R (1999) Feasibility of a rapid dipstick antigen-capture assay for self-testing of travellers' malaria.Trop Med Int Health 4: 442-447.

29. Organisation mondiale du tourisme. www.unwto.org Accès le 29.01.2016.

30. WHO (2015) World Malaria Report 2015.

31. Behrens RH, Bisoffi Z, Björkman A, Gascon J, Hatz C, et al. (2006) Malaria prophylaxis policy for travellers from Europe to the Indian Subcontinent. Malar J 5: 7.

32. Schlagenhauf P, Hommel M (2011) Travellers' malaria-'one shoe does not fit all'. Malar J 10: 129. 


\section{Journal of Infectious Diseases \& Travel Medicine}

33. Genton B, D'Acremont V (2012) Malaria prevention in travelers. Infect Dis Clin North Am 26(3): 637-654.

34. Chen LH, Wilson ME, Schlagenhauf P (2007) Controversies and misconceptions in malaria chemoprophylaxis for travelers. JAMA 297: 22512263.

35. Steinhardt LC, Magill AJ, Arguin PM (2011) Review: Malaria chemoprophylaxis for travelers to Latin America. Am J Trop Med Hyg 85:1015-1024.

36. Calleri G, Behrens RH, Bisoffi Z, Bjorkman A, Castelli F, et al. (2008) Variability in malaria prophylaxis prescribing across Europe : A Delphi method analysis. J Travel Med 15: 294-301.

37. Overbosch D, Schilthuis H, Bienzle U, Behrens RH, Kain KC, et al. (2003) Atovaquone-Proguanil versus Mefloquine for malaria prophylaxis in nonimmune travelers: Results from a randomized, double-blind study. CID 33 (7): 1015.

38. Schlagenhauf P, Tschopp A, Johnson R, Nothdurft HD, Beck B, et al. (2003) Tolerability of malaria chemoprophylaxis in non-immune travellers to sub-
Saharan Africa : Multicentre, randomised, double blind, four arm study. BMJ 327: 1078.

39. Loscher T, Nothdurft HD (2001) Malaria-rapid diagnostic tests and emergency self-medication. Ther Umsch 58: 352-361.

40. Landry P, Iorillo D, Darioli R, Burnier M, Genton B.et al. (2006) Do travelers really take their mefloquine malaria chemoprophylaxis ? Estimation of adherence by an electronic pillbox. J Travel Med 13: 8-14.

41. Huzly D, Schönfeld C, Beuerle W, Bienzle U (1996) Malaria chemoprophylaxis in German tourists : A prospective study on compliance and adverse reactions. J Travel Med 3: 148-155.

42. Behrens RH, Carroll B, Beran J, Bouchaud O, Hellgren $\mathrm{U}$, et al. (2007) The low and declining risk of malaria in travellers to Latin America: Is there still an indication for chemoprophylaxis ?. Malar 6: 114.

43. Mulley AG, Trimble C, Elwyn G (2012) Stop the silent misdiagnosis: Patients' preferences matter. BMJ 345: e6572. 